\title{
A RELAÇÃO SUJEITO/LINGUAGEM NA CONSTRUÇÃO DA IDENTIDADE SURDA
}

\author{
Cínthia NaJLa FAHL Giammelaro* \\ ZILDA MARIA GESUELI* \\ IVANI RODRIGUES SILVA ${ }^{* * *}$
}

\begin{abstract}
RESUMO: O estudo destaca o papel do instrutor surdo no processo de construção da(s) identidade(s) surda(s). Para isso, foram analisadas filmagens da interação de crianças surdas com instrutores surdos, buscando, a partir da convivência cotidiana entre esses sujeitos, levantar aspectos relevantes da aquisição da Língua Brasileira de Sinais (Libras) e da importância do instrutor surdo neste processo. A pesquisa qualitativa utilizou como instrumento um banco de dados do Programa Infantil: Linguagem e Surdez, o qual atende crianças surdas de 4 a 9 anos de idade, realizado em um centro de estudos e pesquisas de uma universidade no interior de São Paulo. As filmagens foram observadas e transcritas da Libras para a escrita do Português. A análise dos dados mostrou que a interação espontânea do instrutor com as crianças constitui os momentos privilegiados de aquisição. Outro aspecto observado, como sendo de extrema importância na formação da(s) identidade(s) surda(s), refere-se à interação destas crianças entre si, entendendo-se como surdas e como usuárias da língua de sinais.
\end{abstract}

Palavras-chave: Surdez. Linguagem. Identidade.

\section{The RELATION SUBJECT/LANGUAGE IN THE DEVELOPMENT OF DEAF'S IDENTITY}

ABSTRACT: This study highlights the importance of deaf instructors during the process of constructing deaf identities. This qualitative study was undertaken at the Children's Program: Language and Deafness - in a Center of studies and research of a University in the State of São Paulo, an outpatient community service for children aged 4 to 9 . We looked at excerpts

\footnotetext{
* Graduada em Fonoaudiologia com aperfeiçoamento em Fonoaudiologia na Área da Surdez na Universidade Estadual de Campinas (Unicamp). E-mail: cinthia.najla@gmail.com

* Doutora em Educação e professora da Faculdade de Ciências Médicas da Universidade Estadual de Campinas (Unicamp). E-mail: zgesueli@fcm.unicamp.br

*** Doutora em Linguística Aplicada e professora da Faculdade de Ciências Médicas da Universidade Estadual de Campinas (Unicamp). E-mail: ivani.rodrigues.silva@gmail.com
} 
filmed during daily contacts between the subjects, in order to reflect upon issues related to deaf identity, including the process of acquisition of Sign Language by deaf children and the role of the instructor in the unfolding of deaf students' interest in this language. The tapes were transcribed from Brazilian Sign Language to Portuguese and subsequently analyzed. The results showed that natural context interactions between deaf instructors and children constituted privileged moments for sign language acquisition. The interaction among the children helps them see themselves as deaf users of sign language, an aspect which is extremely relevant to the constitution of deaf identity.

Key words: Deafness. Language. Identity.

\section{LA RELATION SUJET/LANGUE DANS LA CONSTRUCTION DE L'IDENTITÉ SOURDE}

RÉSUMÉ: L'étude rélève le rôle de l'instructeur sourd dans le processus de construction de $\mathrm{l}^{\prime}$ identité sourde. Pour cela, ont été analysées des prises de vues de l'interaction entre des enfants sourds avec des instructeurs sourds eux-aussi, en cherchant, à partir de la vie quotidienne entre ces sujets, démontrer les aspects importants de l'acquisition de la Langue des Signes Brésilienne (Libras) et de l'importance de l'instructeur sourd dans ce processus. La recherche qualitative a utilisé comme instrument une banque de données du Programme Infantile: Langue et Surdité, qui accueille des enfants sourds de 4 à 9 ans, réalisé dans un Centre d'études et recherches d'une Université à l'intérieur de l'État de São Paulo. Les prises de vues ont été observées et transcrites de la Langue des Signes Brésilienne (Libras) pour le Portugais. L'analyse des données a montré que l'interaction spontanée de l'instructeur avec les enfants constituent les moments privilégiés d'acquisition. Un autre aspect observé d'extrême importance dans la formation de $l^{\prime}$ identité sourde se rapporte à l'interaction de ces enfants entre eux, en se comprenant comme sourds et comme usagers de la langue des signes.

Mots-clés: Surdité. Langue. Identité.

\section{Introdução: diferentes abordagens na educação de surdos}

s modificações ocorridas no decorrer da história ocasionaram diferentes
olhares a respeito da surdez. Na Antiguidade, o sujeito surdo era visto
como incapaz, e, pelo fato de não ouvir e não desenvolver naturalmente a oralidade, ser surdo significava não falar e, portanto, não ser humano (SKLIAR, 1998).

No início do século XVI, surgem relatos de diversos educadores dispostos a trabalhar com surdos, considerando as suas possibilidades de aprendizagem. $\mathrm{O}$ objetivo educacional era desenvolver o pensamento, aquisição de conhecimentos e a comunicação com o mundo ouvinte, buscando, assim, ensinar os surdos a compreender a língua falada. Desse modo, na área educacional havia um acordo unânime 
de que os surdos deveriam adquirir a língua dos ouvintes da sociedade na qual viviam, sendo que somente se beneficiavam deste trabalho os surdos pertencentes a famílias nobres e influentes, para que assim pudessem alcançar seus direitos legais (LACERDA, 1998).

No início do século XVIII surge um novo olhar sobre a educação de surdos que se inicia na França, com o trabalho do abade Charles Michel De L'Epée, o qual, a partir da observação de grupos de surdos, verifica que estes desenvolvem uma comunicação viso-gestual e, com base nesta comunicação, desenvolve o sistema educacional dos "sinais metódicos". De acordo com esta proposta, os educadores deveriam aprender estes sinais para melhor se comunicarem com os surdos e, a partir daí, ensiná-los a língua falada e escrita do grupo majoritário (idem, ibid.).

Ao mesmo tempo em que De L'Epée divulgava seu trabalho com o gestualismo, muitos educadores acreditavam em uma visão oposta e desenvolviam um outro modo de trabalhar com os surdos: o oralismo - fundado pelo alemão e pedagogo renomado Heinicke. Para este, "o pensamento só é possível através da língua oral, e depende dela" (LACERDA, op. cit., p. 72).

De acordo com Trenche (1995), para os oralistas, a forma de comunicação prioritária para os surdos é a linguagem falada, uma vez que esta é indispensável para o desenvolvimento integral das crianças.

Para Skliar (1998), os modelos fundamentais existentes na instituição oralista são ouvintes. Assim, o tempo de interação e de identificação entre os surdos de diferentes idades é escasso, evitando-se contágios "gestuais" entre os alunos. Os adultos surdos presentes na instituição são isolados ou levados a cumprir tarefas longe das crianças, além do que as estas passam o tempo livre com a família ouvinte.

Ainda segundo o autor, foram mais de cem anos de práticas (desde o II Congresso Internacional de Milão, em 1880) visando a correção, a normalização do sujeito surdo, buscando o disciplinamento de seu comportamento e corpo para produzir surdos aceitáveis para a sociedade ouvinte. Além das práticas simplesmente destinadas a fazer com que os surdos fossem como os ouvintes, existiam ainda outros pressupostos, como os filosóficos - o oral como abstração e o gestual como sinônimo de obscuridade do pensamento -, os religiosos - a importância da confissão oral - e os políticos - a necessidade da abolição dos dialetos já dominantes nos séculos XVIII e XIX.

Como o objetivo principal torna-se a aquisição da língua oral, outros objetivos como, por exemplo, a aquisição da língua escrita, a aprendizagem de conteúdos escolares ou a integração ao mundo do trabalho tornam-se problemas secundários, condicionados a um hipotético futuro educativo (SKLIAR, op. cit.). 
Com os resultados insatisfatórios em relação à educação de surdos decorrentes do oralismo, outras propostas de trabalho pedagógico-educacional surgiram, sendo que a tendência, na década de 1970, foi a chamada Comunicação Total. Tal filosofia permitia ao surdo valer-se de todas e quaisquer possibilidades de comunicação. Desse modo, o surdo poderia utilizar-se de fala, leitura orofacial, gestos, sinais, escrita/leitura e amplificação sonora (MOURA; LODI; HARRISON, 1997).

Esta abordagem educacional denominada de filosofia e não de metodologia era a de fornecer à criança surda a possibilidade de desenvolver uma comunicação real com seus pais e professores, para que assim ela pudesse construir seu mundo interno. Segundo Ciccone (1990), esta filosofia procura respeitar tanto a diferença da pessoa surda como a situação ouvinte dos pais.

De acordo com Góes e Souza (1998), a Comunicação Total apenas conferiu ao oralismo uma nova roupagem ideológica, já que esta prática pedagógica permite ao surdo valer-se de sinais, marca linguística de sua diferença, sem que se perca de vista, no entanto, o principal objetivo educacional: o domínio pelo aluno surdo da língua majoritária.

Nesta abordagem os sinais acabam ocupando um lugar de auxiliar da fala. Sendo assim, os alunos não aprendem a compreender os sinais como língua, não ocorrendo, portanto, um efetivo desenvolvimento linguístico.

A prática da Comunicação Total permitiu, contudo, um maior contato com os sinais, anteriormente proibidos pelas estratégias oralistas. Assim, foram surgindo diversos estudos a respeito da língua de sinais que, somados ao fracasso da Comunicação Total, revelaram uma nova abordagem educacional: o bilinguismo.

A abordagem bilíngue diferencia-se da oralista ao considerar o canal viso-gestual fundamental para a aquisição de linguagem do surdo e, ainda, contrapõe-se à Comunicação Total ao preservar um espaço efetivo para a língua de sinais no trabalho educacional, defendendo a ideia de que cada uma das línguas apresentadas ao surdo deve manter suas características próprias. A educação bilíngue para surdos entende a língua de sinais como a língua natural do sujeito surdo, ou seja, L1, e a língua majoritária, no caso o português, como L2, como segunda língua. Assim, o português oral e escrito se dará em um processo de aquisição de segunda língua.

Segundo Gesueli (2006), a proposta de educação bilíngue refere-se, principalmente, à condição bilíngue do surdo, que deverá ter acesso à língua de sinais por meio do contato com a comunidade surda, sendo a língua majoritária, oral e escrita, trabalhada como segunda língua.

Vale ressaltar que a adesão a uma proposta de educação bilíngue retoma a figura que foi apagada, negada na era oralista: a do adulto surdo, o qual tem um 
papel definitivo no processo de aquisição de L1 e, consequentemente, na construção $\mathrm{da}(\mathrm{s})$ identidade(s) surda(s), pois ele constitui-se como interlocutor privilegiado da criança surda (GESUELI, op. cit.).

Tal abordagem envolve não apenas questões linguísticas, mas também políticas relativas à identidade e à cultura dos participantes das comunidades surdas. A partir daí, muitos movimentos sociais são alavancados pelos próprios surdos, culminando com o reconhecimento da Língua Brasileira de Sinais (Libras) como língua nacional no país, pela Lei Federal n. 10.436, de 24 de abril de 2002 (QUADROS, 2006), e pelo Decreto n. 5.626, de 22 de dezembro de 2005, que regulamenta a lei federal.

\section{Concepções de surdez}

Não apenas as abordagens educacionais foram sofrendo modificações no decorrer da história, como também os olhares a respeito da surdez e do surdo foram transformados.

Assim, considerando as diferentes correntes teórico-educacionais enfocando o sujeito surdo, pode-se dizer que cada uma delas é vinculada a uma concepção de surdez.

De acordo com Carvalho e Levy (1999), a abordagem oralista, que tem como principal objetivo a língua oral para, desta maneira, inserir o surdo na comunidade dos ouvintes, entende a surdez como uma deficiência a ser tratada, minimizada por meio da construção de uma personalidade ouvinte no sujeito surdo.

Para Skliar (1997), a concepção de surdez imposta pelo oralismo enquadra-se em um modelo clínico-terapêutico e, assim, impõe uma visão estritamente ligada à patologia, ao déficit biológico, traduzindo-se educativamente em estratégias corretivas e reparadoras. O surdo é visto pelo que lhe falta, a educação se converte em terapêutica e o objetivo escolar passa a ser o de fornecer ao surdo o que ele não tem, ou seja, a audição ou, ainda, uma identidade ouvinte deteriorada.

Segundo o mesmo autor, a organização metodológico-institucional do oralismo representa a medicalização da surdez, que busca a cura do problema auditivo, a correção dos problemas de fala e o treinamento da leitura labial e da articulação. Portanto, as instituições baseadas em tal abordagem são organizadas para controlar, separar e negar a existência da comunidade surda, da língua de sinais, das identidades surdas e das experiências visuais, que determinam o conjunto de diferenças dos surdos em relação a qualquer outro grupo de sujeitos (SKLIAR, 1998).

Skliar (op. cit.) refere-se às práticas oralistas como fazendo parte de uma ideologia que denomina ouvintismo. Segundo ele (p. 15), o ouvintismo "trata-se de um 
conjunto de representações dos ouvintes, a partir do qual o surdo está obrigado a olhar-se e a narrar-se como se fosse ouvinte".

Ainda segundo Perlin (1998), academicamente, a palavra ouvintismo designa o estudo do surdo a partir da deficiência, da clinicalização e da necessidade de normalização. No entanto, de acordo com Skliar (op. cit.), na tentativa de olhar-se e narrar-se como ouvinte, o surdo percebia-se como deficiente, como não ouvinte. O mesmo autor relata ainda que, segundo suas pesquisas, o olhar dos surdos sobre o fracasso do oralismo "se refere, sobretudo, a uma questão ligada à falta de acesso à língua de sinais e a um processo demorado de identificações com outros surdos" (p. 19).

Com a filosofia da Comunicação Total surge a possibilidade de o surdo ser visto de maneira diferente, segundo Ciccone (1990, p. 6), essa filosofia educacional "entende o surdo como uma pessoa, e a surdez como uma marca, cujos efeitos adquirem, inclusive, as características de um fenômeno com significações sociais".

Entretanto, é somente a partir da emersão das ideias ligadas ao bilinguismo que surge uma nova concepção de surdez, vendo o sujeito surdo como diferente e não mais como deficiente ou anormal. Ao assumir essa concepção de surdez, McLaren (1995, apud SKLIAR, op. cit., p. 13) relata entender "diferença" "não como um espaço retórico - a surdez é uma diferença - mas como uma construção histórica e social, efeito de conflitos sociais, ancorada em práticas de significação e de representações compartilhadas entre os surdos".

Segundo Gesueli (2006), a nova concepção de surdez na qual se baseia o bilinguismo implica mudanças ideológicas que rompem, de fato, tanto com a concepção oralista, quanto, em grande parte, com os sistemas da Comunicação Total.

Skliar (1997) sugere, então, duas concepções de surdez: a primeira com base no modelo clínico-terapêutico, na qual a surdez é vista como condição patológica, e o surdo como deficiente, e a segunda, baseada em uma perspectiva socioantropológica da surdez, na qual o surdo é concebido como diferente e a surdez, compreendida como uma experiência visual.

A partir desta segunda perspectiva, temos o bilinguismo, o qual não confere ao déficit auditivo um papel relevante, mas importa uma educação que se sustente nas interações habituais dos surdos entre si e que, principalmente, tenha como traço fundamental a língua de sinais como identificação sociocultural. Pode-se permitir aos surdos formar uma comunidade linguística minoritária caracterizada por compartilhar, além da língua de sinais, valores culturais, hábitos e modos de socialização (SKLIAR, 1997). 
Ainda segundo Skliar (op. cit.), o modelo bilíngue permite ao surdo criar uma identidade bicultural, uma vez que a criança pode desenvolver suas potencialidades, inserida na cultura surda, e assim, aproximar-se da cultura ouvinte.

\section{Relacionando linguagem e identidade (surda)}

O papel do adulto surdo no cotidiano da criança surda mostra-se de extrema importância na construção da identidade, dado o fato de que linguagem/sujeito/ identidade estão intrinsecamente relacionados.

Bakhtin (1997, p. 302) aponta que "aprender a falar é aprender a estruturar enunciados", sendo que os enunciados produzidos sempre estão cheios de ecos e lembranças resultantes de outros enunciados já ditos, vinculados à esfera da comunicação verbal.

Segundo Vygotsky (1991), é, principalmente, com a ajuda da fala que a criança começa a controlar o ambiente e a organizar seu próprio comportamento.

Já de acordo com Geraldi (1997), a linguagem é que dá a condição para os sujeitos de compreender o mundo e nele agir, sendo que nem sempre a construção dos modos de ver o mundo é harmônica. Mesmo que os interlocutores compartilhem suas crenças, estes sempre estão se reorganizando pelo discurso.

Levando em consideração o papel constitutivo da linguagem e, ainda, que o sujeito se constitui na medida em que interage com outros, pode-se dizer que tanto a língua quanto o sujeito constituem-se nos processos interativos. Não há um sujeito dado, pronto, que entra em interação, mas sim um sujeito que vai se construindo e se completando em suas próprias falas, e nas falas dos outros (GERALDI, 1997).

Segundo Rajagopalan (2006, p. 42), "a identidade de um indivíduo se constrói na língua e através dela", sendo que não há uma identidade fixa anterior e fora da língua, as identidades estão sempre em estado de fluxo, uma vez que a língua em si é uma atividade em evolução. Partilhando o mesmo ponto de vista, Maher (2006, p. 117) ressalta que "é, principalmente, no uso da linguagem que as pessoas constroem e projetam suas identidades". De acordo com Dizeu e Caporali (2005, p. 587),

A partir da aquisição da língua, a criança passa a construir sua subjetividade, pois terá recursos para sua inserção no processo dialógico de sua comunidade, trocando idéias, sentimentos, compreendendo o que se passa em seu meio e adquirindo, então, novas concepções de mundo.

O mesmo processo acontecerá com a criança surda: ao adquirir a língua de sinais se tornará capaz de significar o mundo (DIZEU; CAPORALI, 2005) e de construir 
sua identidade, uma vez que "a construção da identidade não é do domínio exclusivo de língua alguma, ainda que ela seja, sempre, da ordem do discurso" (MAHER, 2006, p. 135).

Assim como qualquer criança em processo de aquisição de sua língua natural, a criança surda adquire a língua de sinais por meio de suas interações cotidianas com a comunidade surda (SKLIAR, 1998). No entanto, sabe-se que as crianças surdas têm poucas oportunidades de adquirir precocemente a língua de sinais, já que a grande maioria da população de surdos é filha de pais ouvintes (GÓES, 2000). É importante ressaltar ainda que os pais ouvintes, logo após o diagnóstico de surdez de seus filhos, acabam desistindo da comunicação com eles, isto em função do período de luto pelo qual esses pais passam e, ainda, pelo fato de se sentirem incomodados por conversar com uma criança que não pode ouvir, o que dificulta o processo de aquisição de linguagem destes sujeitos (SILVA, 2005).

Faz-se relevante, então, ressaltar o papel do instrutor surdo como interlocutor privilegiado da criança surda (GESUELI, 2006).

Skliar e Lunardi (2000) acreditam que o papel do professor surdo vai muito além de apenas uma identificação linguística. Para eles, o professor surdo deve aproveitar o espaço escolar para construir, juntamente com seus pares, estratégias de identificação vislumbradas num processo sócio-histórico amplo, não fragmentado. Estratégias que não são fixas e nem homogêneas, construídas dentro de um contexto político.

De acordo com Dizeu e Caporali (2005), para que o surdo se reconheça como tal é importante que este estabeleça o contato com a comunidade surda, para que, desse modo, aconteça a identificação com a cultura, os costumes, a língua e, principalmente, com a diferença de sua condição.

Assumiremos neste trabalho o conceito de identidade pós-moderna (HALL, 2003), ou seja, identidades fragmentadas, plurais, algumas vezes contraditórias ou até não resolvidas. A partir de tais considerações, falar de identidade(s) surda(s) é conceber a surdez como diferença e, ainda, entender as identidades como construídas num processo histórico, vendo-as sempre em processo de construção e reconstrução (SKLIAR; LUNARDI, 2000).

De acordo com Perlin (1998, p. 54) a identidade surda "é uma identidade subordinada com o semelhante surdo [...] o encontro surdo-surdo é essencial para a construção da identidade surda".

Durante muito tempo o oralismo buscou a normalização do surdo por meio da construção de uma identidade ouvinte, tomando, portanto, como referência o adulto ouvinte. Para Skliar (1998), a intenção de transformar as crianças surdas em adultos ouvintes originou um doloroso jogo de ficção nas identificações e identidades surdas. 
A emersão do bilinguismo criou a necessidade da inclusão da criança surda na comunidade surda, o que, consequentemente, destacou a importância do adulto surdo no dia a dia da criança, auxiliando na construção de sua identidade.

Perlin (1998) cita que o adulto surdo, em contato com outros surdos, construirá uma identidade fortemente centrada no ser surdo, a "identidade política surda". Segundo a autora, a educação deve caminhar no sentido da identidade do surdo, permitindo, para isso, a presença do professor surdo. Ainda para Perlin (op. cit., p. 57), a experiência que separa a identidade surda e a identidade ouvinte é a visual, "a identidade surda se constrói dentro de uma cultura visual", sendo que essa construção não é isolada, mas sim multicultural.

No rastro de tal discussão, pretendemos, nesta pesquisa, observar o papel do professor surdo, "interlocutor privilegiado" da criança surda, na construção da identidade destes alunos que se encontram em atendimento em um centro de estudos e pesquisas de uma universidade situada no interior de São Paulo.

\section{Método}

Trata-se de um estudo qualitativo, tendo como instrumento um banco de dados coletado em um centro de estudos e pesquisas de uma universidade no interior de São Paulo. Os sujeitos da pesquisa possuem faixa etária entre 4 e 9 anos de idade, sendo todos filhos de pais ouvintes. Quanto ao instrutor surdo, do sexo masculino, ele atua na instituição desde 1995, quando se deu a implantação de um projeto educacional bilíngue, o qual concebe a língua brasileira de sinais (Libras) como a primeira língua a ser adquirida pela criança surda e a língua oral e escrita como segunda língua, garantindo a interação com surdos adultos fluentes em Libras.

A partir da metodologia utilizada para a realização deste estudo, pode-se afirmar que se trata de uma pesquisa documental por meio de filmagens. Segundo Cruz Neto (1994), a utilização de filmagens proporciona documentar momentos ou situações que ilustram o cotidiano vivenciado; permite, ainda, reter vários aspectos do universo pesquisado.

As fitas foram observadas e os episódios que marcaram a interação do professor surdo com as crianças surdas foram transcritos da Libras para a escrita do Português, sendo, posteriormente, analisados. As filmagens puderam ser analisadas graças a um Termo de Consentimento Livre e Esclarecido assinado pelos responsáveis da criança, assim que esta inicia atendimento no centro estudado. Os critérios utilizados na coleta de dados e filmagens foram:

- As atividades propostas e desenvolvidas pelo instrutor surdo na interação com as crianças sujeitos da pesquisa. 
- Observar se as atividades desenvolvidas abordam o tema da(s) identidade(s) surda(s).

- Observar o quanto estas atividades favorecem ou não a construção da(s) identidade(s) surda(s).

- Considerar as relações que se estabelecem entre instrutor surdo e crianças surdas no processo de aprendizagem.

- Observar o interesse das crianças sobre o uso da língua de sinais.

- Observar a construção narrativa dos sujeitos da pesquisa, tanto professor surdo quanto crianças surdas.

- Observar as possibilidades de fluência na Libras por parte das crianças sujeitos da pesquisa.

- Observar a interação criança/criança no que se refere ao entendimento e construção da(s) identidade(s) surda(s).

Como o propósito foi observar a construção da(s) identidade(s) surda(s), a análise dos dados foi realizada com base na interação crianças surdas/instrutor surdo em contextos clínicos e educacionais, com o objetivo de verificar a influência do instrutor surdo no processo de construção dessa(s) identidade(s).

\section{Resultados e discussão}

Para a transcrição dos dados foram utilizados os mesmos parâmetros propostos por Góes e Souza (1998). Desse modo, os enunciados sinalizados aparecem em caixa alta, registrados em ordem de ocorrência e mantendo-se os verbos no infinitivo, uma vez que, na Libras, a marcação de tempo é de natureza discursiva e não morfológica. As falas foram reproduzidas em caixa baixa e, quando acompanhadas da letra $S$ entre parênteses, mostram a ocorrência de sinalização do item imediatamente anterior. No decorrer das transcrições, as situações e o contexto dos episódios foram descritos entre parênteses e em caixa baixa e, ainda, alguns recortes sinalizados da seguinte forma: (...), indicando a transição de um recorte a outro inserido em um mesmo episódio. Os nomes citados nas transcrições são fictícios para que a identidade dos sujeitos da pesquisa seja preservada.

\section{Episódio 1}

Participam da atividade: o instrutor surdo, uma estagiária ouvinte e três crianças surdas - Ana, Paulo e Tiago, com, aproximadamente, 4 anos de idade. Nesta 
atividade, o instrutor está sentado com as crianças ao redor de uma mesa, mostrando-lhes um livro com várias ilustrações. No decorrer da atividade, o instrutor descreve às crianças o que o personagem está desempenhando em cada ilustração.

(A estagiária chama a atenção de Ana, tocando sua mão, e aponta uma ilustração no livro)

T1 Ana: (Vendo o que a estagiária está apontando, e que esta colocou a mão sobre o livro) NÃO (aponta para o instrutor) VER LER (porque este tinha pedido para que as crianças não colocassem a mão sobre o livro)

(A estagiária concorda com Ana, gesticulando que sim com a cabeça)

(...)

(O instrutor tenta chamar a atenção de Tiago, tocando suas mãos, virando seu rosto. No entanto, Tiago não se vira para ele. Então, o instrutor chama a atenção de Ana, fazendo o mesmo. Ana olha para o instrutor e, logo em seguida, chama a atenção de Tiago, apontando para o instrutor, para que Tiago olhe para ele)

T2 Instrutor: ESCURO NOITE CANSADO IR DORMIR CAMA (aponta a figura) CAMA

T3 Ana: ESCURO (realizando o sinal voltada para Tiago)

(...)

T4 Instrutor: LUA (sinalizando para Ana)

(Ana tenta realizar o sinal, mas não consegue formar a configuração de mão convencional, então o instrutor mostra à criança os dois dedos que são utilizados para a realização do sinal. Ana realiza a configuração convencional e sinaliza)

T5 Ana: LUA

T6 Instrutor: (apontando o desenho da lua na ilustração) LUA

T7 Ana: LUA

T8 Instrutor: CAMA (apontando o desenho da cama) CAMA

T9 Ana: CAMA (imitando o sinal que o instrutor havia realizado)

T10 Instrutor: (aponta para uma figura e sinaliza) RELÓGIO CUCO

T11 Ana: RELÓGIO (em seguida aponta a figura do relógio)

Depois de mostrar às crianças as ilustrações do livro, o instrutor pega alguns animais de brinquedo que foram tratados na aula anterior, senta-se no chão com as crianças e pede para que estas realizem os sinais dos animais.

\section{(...)}

T12 Instrutor: (mostrando o sapo, pergunta) SINAL (espera um tempo e então sinaliza) SAPO

T13 Ana: SAPO

T14 Tiago: SAPO 
T15 Instrutor: (chama a atenção de Tiago, tocando suas mãos) VER

T16 Tiago: SAPO

(O instrutor entrega o sapo para Ana e então pega o coelho)

T17 Instrutor: SINAL (perguntando)

(Ana não realiza o sinal, então o instrutor pega o sapo de suas mãos, mostra o coelho e sinaliza)

T18 Instrutor: COELHO VOCÊ (apontando para Ana para que esta realize o sinal)

(A estagiária pega a mão de Ana e ajuda-a a formar a configuração de mão convencional para a realização do sinal, depois faz o sinal para que Ana veja como é realizado)

T19 Estagiária: COELHO

T20 Ana: COELHO

(O instrutor volta-se para Tiago)

T21 Instrutor: VER VOCÊ (apontando para Tiago para que este realize o sinal)

T22 Tiago: COELHO

T23 Ana: COELHO

Desse modo, o instrutor vai mostrando os demais animais para as crianças e pedindo para que estas realizem os respectivos sinais. Após a nomeação dos animais o instrutor permite que as crianças brinquem com estes.

(Tiago percebe que um dos brinquedos faz barulho, então começa a apertá-lo em sua própria orelha e na orelha de Ana)

T24 Instrutor: OUVIR OUVIR (percebendo o que Tiago estava fazendo)

(O instrutor pega o brinquedo de Tiago, aperta-o na própria orelha e sinaliza)

T25 Instrutor: OUVIR

T26 Ana: (aponta a própria orelha) OUVIR (então vira a cabeça para que o instrutor aperte o brinquedo em sua outra orelha)

(O instrutor aperta o brinquedo na orelha de Ana, que ri)

T27 Instrutor: OUVIR

(O instrutor pega a mão de Tiago e leva até sua orelha)

T28 Instrutor: OUVIR

T29 Tiago: OUVIR

Logo no início do episódio, pode-se observar a percepção que as crianças têm do instrutor como autoridade que impõe regras, as quais devem ser seguidas. Como visto no primeiro turno, o instrutor havia dito anteriormente para as crianças 
não tocarem no livro porque ele é quem estava mostrando as figuras. Assim, no momento em que a estagiária ouvinte aponta uma figura no livro para Ana, esta se vira para ela sinalizando que não deveria tocar no livro porque era o instrutor quem estava mostrando as figuras. O instrutor havia imposto uma regra, que deveria ser respeitada inclusive pela estagiária ouvinte.

Pode-se dizer, também, que neste episódio o instrutor utiliza um livro. No entanto, não há nele uma narrativa da história, mas sim uma descrição de suas ilustrações, uma preocupação com a nomeação das figuras. Vale ressaltar que a descrição das figuras está relacionada com a importância do aspecto visual para o sujeito surdo, uma vez que a língua de sinais é uma língua viso-gestual e a surdez uma experiência visual.

Nas primeiras filmagens analisadas, observamos que a interação das crianças surdas entre si limitava-se a disputas por brinquedos, espaço, entre outros, sendo que a maior parte das interações ocorria entre criança e instrutor ou criança e estagiária (criança-adulto). No entanto, neste episódio, nos turnos 2 e 3, nota-se uma mudança na interação entre Ana e Tiago (criança-criança), uma vez que Ana apresenta intenção dialógica ao interagir com Tiago. Tal situação mostra o processo de aquisição da língua de sinais marcado, inicialmente, pela interação com o adulto que favorece a tomada de turno pela criança, assumindo papéis anteriormente exclusivos do adulto (DE LEMOS, 1986).

Pode-se notar ainda nos turnos 4 e 5, bem como nos 18 a 20, uma preocupação do instrutor na correção dos sinais realizados pelas crianças de forma não convencional. Com a correção, o instrutor busca legitimar o uso da língua de sinais pelas crianças, para que estas realmente adquiram a língua e, a partir daí, possam construir uma identidade. Sobre este aspecto pode-se dizer, ainda, que a criança aceita a intervenção e a relação de autoridade do instrutor surdo, como interlocutor privilegiado fluente em língua de sinais.

\section{Episódio 2}

Participam da atividade: o instrutor surdo e quatro crianças surdas - Adriano, Alice, Júlio e Keila, entre 8 e 9 anos de idade. Nesta atividade o instrutor narra às crianças a história da "Cinderela surda" e, em seguida, utiliza o computador no qual foram arquivadas figuras do livro. Assim, o instrutor relembra a história juntamente com as crianças.

\section{$(\ldots)$}

T20 Instrutor: CINDERELA TER DUAS IRMÃS (aponta na ilustração as duas irmãs) TRÊS IRMÃS (aponta Cinderela na figura) SURDA (aponta as duas irmãs de Cinderela) 
SURDA SABER SINAIS (aponta Cinderela) SURDA BOM SINAIS APRENDER ESSA HISTÓRIA MOSTRAR TER FAMÍLIA PAI MÃE

T21 Instrutor: PAI

T22 Instrutor: PRESTAR ATENÇÃO (o instrutor chama a atenção de Alice que dialoga com Keila, tocando-a, e continua a história)

T23 Instrutor: PAI MÃE MORRER AGORA TER OUTRA MADASTRA (aponta uma das irmãs de Cinderela) MÃE (aponta a outra irmã) MÃE

T24 Instrutor: AGORA TER (aponta a figura no computador) ESTUDAR CASTELO LÁ (estabelecendo um lugar no espaço para representação de castelo. Em seguida aponta a ilustração no computador) PRÍNCIPE ESTUDAR APRENDER SINAIS ALFABETO (aponta na figura uma lousa e um personagem) PROFESSOR ENSINAR CASTELO LÁ CASTELO (aponta o príncipe na ilustração) APRENDER ALFABETO SINAIS (aponta mais uma vez figura do príncipe) É SURDO

T25 Instrutor: ENSINAR ESCREVER (apontando a ilustração da lousa no computador) A B C D E F G (aponta mais uma vez a ilustração) SABER PROFESSOR SABER SINAIS AGORA CINDERELA SABER MÃE MORRER CHORAR

(Alice toca o instrutor chamando sua atenção)

T26 Alice: (perguntando) SURDA SURDA

T27 Instrutor: (aponta a figura, sinalizando que sim com a cabeça) SURDA

(Alice faz expressão de surpresa)

T28 Instrutor: CHORAR MÃE MORRER PASSADO AGORA PAI MORRER TAMBÉM

T29 Alice: (perguntando) DOIS

T30 Instrutor: (confirmando com a cabeça) DOIS (aponta a figura) ANTES PAI (vira o rosto de Alice para que ela olhe para ele) PAI ANTES CASAR (aponta novamente a figura no computador)

(O instrutor vira-se para Alice e Keila, que estão dialogando)

T31 Instrutor: PRESTAR ATENÇÃO (aponta a figura) PAI CASAR

T32 Keila: ADRIANO

(Adriano vira-se para Keila)

T33 Keila: PAI MORRER

(O instrutor chama a atenção de Adriano para que este continue prestando atenção na história)

T34 Instrutor: AGORA PAI MORRER ACABAR (aponta para a figura) CHORAR TRISTE PAI MORRER

(Alice chama a atenção do instrutor, tocando-o, e este se vira para ela)

T35 Alice: ADRIANO MORRER PAI (aponta para Adriano)

T36 Instrutor: CERTO

(O instrutor continua contando a história) 
A história mostra protagonistas surdos, usuários da Libras, a Cinderela é surda, turno 20, assim como o príncipe também é surdo e estudava para aprender sinais, tendo um professor que sabe sinais, turnos 24 e 25 . Tal fato não é frequente em histórias e contos infantis, o que justifica, nos turnos 26 e 27, a surpresa de Alice ao realmente se dar conta de que Cinderela era surda.

Um fato interessante ocorre no momento em que o instrutor trata sobre a morte do pai de Cinderela, instante no qual as crianças realizam um paralelo com um fato recente, a morte do pai de Adriano, tecendo comentários com o próprio colega e com o instrutor, o que não seria possível se as crianças não tivessem adquirido uma língua: turnos 32 a 33 e 35 a 36.

Ainda no turno 32, nota-se que Keila, ao referir-se a Adriano, utiliza o sinal de identificação do colega, que é de extrema importância para o sujeito surdo, pois enquanto os ouvintes se identificam pelos nomes, os surdos se identificam pelos sinais que representam. Essa interação é muito importante para a construção da identidade, já que, segundo Perlin (1998), o encontro surdo-surdo é essencial para a construção da identidade do sujeito surdo.

\section{Episódio 3}

Participam da atividade: o instrutor surdo e quatro crianças surdas - Alice, Bruno, Júlio e Keila, entre 8 e 9 anos de idade, que participavam do programa no período da tarde.

Nesta atividade, o instrutor relembra com as crianças a história da Cinderela Surda que havia contado em outra atividade e, em seguida, pede para que as crianças contem a história baseadas nas figuras do livro.

(O instrutor relembra com as crianças a parte da história na qual a mãe de Cinderela morre)

T1 Keila: CACHORRO MORRER MEU PEQUENO MORRER (vira-se para Alice) PEQUENO MORRER CACHORRO MORRER PAI JOGAR FORA CHEIRAR MAL

T2 Instrutor: (representa com as mãos o príncipe e a Cinderela andando juntos e sentando-se) SINAIS CONVERSAR COMEÇAR NAMORAR ABRAÇAR

(Enquanto o instrutor narra essa parte da história, Alice e Keila imitam os sinais realizados por ele, brincando)

(...)

T3 Instrutor: (encena o mensageiro do castelo procurando mais alguma moça na casa e encontrando Cinderela) PERGUNTAR AQUELA MADRASTA FALAR ELA SURDA (representa a expressão da madrasta de Cinderela, como que dizendo que não tinha 
que chamá-la) PODER CHAMAR (representa Cinderela experimentando a luva e esta servindo perfeitamente em suas mãos) MADRASTA DUAS IRMÃS SURPRESA (perguntando) $\mathrm{COMO}$

(O instrutor finaliza a história narrando que Cinderela mudou-se para o castelo e casou-se com o príncipe)

Em seguida, o instrutor pede para que as crianças narrem a história e, assim, ele vai mostrando figuras às crianças e cada uma delas vai contando uma parte.

\section{$(\ldots)$}

T4 Alice: CINDERELA PRÍNCIPE SINAIS (vira-se para a filmadora) SINAIS INSTRUTOR (realiza o sinal de identificação do instrutor) SINAIS INSTRUTOR (repete o sinal de identificação do instrutor) SINAIS FALAR

(...)

T5 Alice: (representa uma moça tentando colocar a luva com esforço) NÃO CONSEGUIR VIR ENCONTRAR IRMÃS (aponta a figura da coroa no livro) SINAL (perguntando ao instrutor qual o sinal para a figura) SINAL

T6 Instrutor: COROA

T7 Alice: COROA

$(\ldots)$

(O instrutor aponta alguns personagens do livro. Conforme aponta os personagens, Alice vai respondendo)

T8 Alice: MULHER SURDA MULHER OUVINTE HOMEM SURDO

Neste episódio, novamente, a partir de um fato da história (a morte do pai da Cinderela), Keila relata algo de sua própria vida, a morte de seu cachorro, o que evidencia o uso da língua de sinais pela criança. Segundo Geraldi (1997), a linguagem dá a condição para os sujeitos de compreender o mundo e nele agir, o que já é perceptível nesses sujeitos, ou seja, a língua de sinais em funcionamento.

No turno 3, o instrutor narra que a madrasta de Cinderela não queria chamá-la para que experimentasse a luva por ela ser surda. No entanto, o mensageiro manda chamá-la mesmo assim, demonstrando que o fato de Cinderela ser surda não a exclui da situação de sujeito protagonista. $\mathrm{O}$ instrutor continua narrando que a luva serviu em Cinderela e que a madrasta e as irmãs ficaram surpresas.

No momento em que as crianças devem contar a história, nos turnos 5 a 7, Alice está narrando uma parte. Porém, não sabe o sinal de uma figura e, então, aponta a figura no livro e pergunta ao instrutor o sinal correspondente a ela, o qual the responde. $\mathrm{O}$ instrutor propicia contexto linguístico para o uso da língua e a criança entende que ele é usuário oficial da língua, ou seja, aquele que legitima o uso da Libras. 
Ainda neste episódio, o instrutor relata às crianças que Cinderela e o príncipe conversavam em sinais, no turno 2. Assim, no turno 4, Alice vira-se para a filmadora, como se estivesse conversando com uma pessoa e repete o que o instrutor havia dito, sinalizando que a Cinderela e o príncipe conversavam em sinais e, ainda, que o instrutor faz sinais, fala em sinais.

Já no final do episódio, no turno 8, o instrutor aponta alguns personagens e Alice vai identificando-os como surdos ou ouvintes. A criança já identifica sujeitos surdos e ouvintes diferenciando os personagens da história, fato que marca o início do processo de construção da(s) identidade(s) surda(s).

Podemos considerar que as crianças, com base na interação adulto surdo/ criança surdo, fazem uso da língua de sinais, o que propicia entendimento sobre sujeitos sinalizadores e sujeitos ouvintes, iniciando o processo de reconhecimento de sua(s) identidade(s) surda(s). Nesta interação, o ser surdo não se constitui como um problema ou uma dificuldade a ser superada, mas sim como sujeitos que fazem uso das mãos para se fazerem entender.

\section{Conclusão}

No decorrer das interações surdo/surdo, observamos a grande preocupação do instrutor em legitimar a língua de sinais, interferindo nas produções das crianças.

No início das interações o instrutor privilegia a nomeação de figuras e objetos e assume o papel de professor "ensinando" a Libras, salientando aspectos desta língua de forma a dar acesso ao seu funcionamento às crianças surdas. Além disso, em momentos nos quais o instrutor se destitui do papel de professor, em interação espontânea, podemos observar também a língua de sinais em funcionamento, sendo estes os momentos privilegiados de aquisição.

Outro aspecto relevante a ser considerado na formação das identidades das crianças é o contato destas com seus pares, identificando-se como iguais, ou seja, como surdos. A partir da institucionalização do instrutor surdo, podemos observar que o reconhecimento da surdez tem-se iniciado mais precocemente, o que antes não acontecia. Somente na idade adulta os surdos se davam conta de sua identidade e, muitas vezes, de forma negativa, subestimando-se em relação aos ouvintes (GESUELI, 2003).

Destacamos, portanto, a importância do instrutor surdo para a formação das identidades da criança surda, sendo ele não somente o interlocutor privilegiado fluente em língua de sinais, mas também a autoridade que legitima a língua, dando-lhe poder no contexto institucional. 


\section{Referências}

BAKHTIN, M. Os gêneros do discurso. In: BAKHTIN, M. Estética da criação verbal. Trad. de Maria Hermantina Galvão Gomes Pereira. São Paulo: Martins Fontes, 1997. p. 277-326.

CARVALHO, A.P.P.; LEVY, C.C.A.C. A história de surdos contada por ouvintes. In: LEVY, C.C.A.C.; SIMONETTI, P. O surdo em si maior. São Paulo: Roca, 1999. p. 11-25.

CICCONE, M. Comunicação total: introdução, estratégia, a pessoa surda. Rio de Janeiro: Cultura Médica, 1990.

CRUZ NETO, O. O trabalho de campo como descoberta e criação. In: MINAYO, M.C.S. (Org.). Pesquisa social: teoria, método e criatividade. 7. ed. Petrópolis: Vozes, 1994. p. 51-66.

DE LEMOS, C.T.G. Interacionismo e aquisição de linguagem. Delta, São Paulo, v. 2, n. 2, p. 231-248, 1986.

DIZEU, L.C.T.B.; CAPORALI, S.A. A língua de sinais constituindo o surdo como sujeito. Educação \& Sociedade, Campinas, v. 26, n. 91, p. 583-597, 2005.

GERALDI, J.W. Portos de passagem. 4. ed. São Paulo: Martins Fontes, 1997.

GESUELI, Z.M. Língua de sinais e aquisição da escrita. In: SILVA, I.R.; KAUCHAKJE, S.; GESUELI, Z.M. (Org.). Cidadania, surdez e linguagem. São Paulo: Plexus, 2003. p. 147-159.

GESUELI, Z.M. Lingua(gem) e identidade: a surdez em questão. Educação $\mathcal{E}$ Sociedade, Campinas, v. 27, n. 94, p. 277-292, 2006.

GÓES, M.C.R. Com quem as crianças surdas dialogam em sinais?. In: LACERDA, C.B.F.; GÓES, M.C.R. (Org.). Surdez, processos educativos e subjetividade. São Paulo: Lovise, 2000. p. 29-49.

GÓES, M.C.R.; SOUZA, R.M. A linguagem e as estratégias comunicativas na interlocução entre educadores ouvintes e alunos surdos. Revista Distúrbios da Comunicação, São Paulo, v. 10, n. 1, p. 59-76, 1998.

HALL, S. A identidade cultural na pós-modernidade. 7. ed. Rio de Janeiro: DP\&A, 2003.

LACERDA, C.B.F. Um pouco da história das diferentes abordagens na educação dos surdos. Cadernos Cedes, Campinas, v. 19, n. 46, p. 68-80, 1998.

MAHER, T.M. Sendo índio em português. In: SIGNORI, I. (Org.). Lingua(gem) e identidade: elementos para uma discussão no campo aplicado. 4. ed. Campinas: Mercado de Letras, 2006. p. 115-138. 
MOURA, M.C.; LODI, A.C.B.; HARRISON, K.M.P. História e educação: o surdo, a oralidade e o uso de sinais. In: LOPES FILHO, O. Tratado de Fonoaudiologia. São Paulo: Roca, 1997. p. 327-357.

PERLIN, G.T.T. Identidades surdas. In: SKLIAR, C.B. A surdez: um olhar sobre as diferenças. Porto Alegre: Mediação, 1998. p. 51-73.

QUADROS, R.M. Políticas linguísticas e educação de surdos em Santa Catarina: espaço de negociações. Cadernos Cedes, Campinas, v. 26, n. 69, p. 141-161, 2006.

RAJAGOPALAN, K. O conceito de identidade em linguística: é chegada a hora para uma reconsideração radical? In: SIGNORI, I. (Org.). Lingua(gem) e identidade: elementos para uma discussão no campo aplicado. 4. ed. Campinas: Mercado de Letras, 2006. p. 21-45.

SILVA, I.R. As representações do surdo na escola e na família: entre a (in)visibilidade da diferença e da deficiência. 2005. 274f. Tese (Doutorado em Linguística) - Instituto de Estudos da Linguagem, Universidade Estadual de Campinas, Campinas.

SKLIAR, C.B. Uma perspectiva sócio-histórica sobre a psicologia e a educação dos surdos. In: SKLIAR, C.B. (Org.). Educação e exclusão: abordagens sócio-antropológicas em Educação Especial. Porto Alegre: Mediação, 1997. p. 105-153.

SKLIAR, C.B. Os estudos surdos em educação: problematizando a normalidade. In: SKLIAR, C.B. (Org.). A surdez: um olhar sobre as diferenças. Porto Alegre: Mediação, 1998. p. 7-31.

SKLIAR, C.B.; LUNARDI, M.L. Estudos surdos e estudos culturais em educação. In: LACERDA, C.B.F.; GÓES, M.C.R. (Org.). Surdez, processos educativos e subjetividade. São Paulo: Lovise, 2000. p. 11-22.

TRENCHE, M.C.B. A criança surda e a linguagem no contexto escolar. 1995. 184f. Tese (Doutorado) - Pontifícia Universidade Católica de São Paulo, São Paulo.

VYGOTSKY, L.S. A formação social da mente: o desenvolvimento dos processos psicológicos superiores. Trad. de José C. Neto, Luis Silveira M. Barreto e Solange C. Afeche. 4. ed. São Paulo: Martins Fontes, 1991.

Recebido em 1ํo de setembro de 2011.

Aprovado em 13 de abril de 2012. 